\title{
Microscopic Examination of Nail Clippings from Patients with Palmoplantar Pustulosis
}

\author{
Anber Ancel Tanaka ${ }^{a}$ Betina Werner ${ }^{b} \quad$ Cassia Farris $^{c}$ Cassio Tornesy ${ }^{c}$ \\ aDepartment of Dermatology, Evangélica Faculty of Paraná, Curitiba, Brazil; bepartment \\ of Pathology, Federal University of Paraná, Curitiba, Brazil; ' Dermatologist, Private Practice, \\ Curitiba, Brazil
}

\section{Keywords}

Nails · Onychodystrophy · Psoriasis · Palmoplantar pustulosis · Nail clipping · Microscopy

\section{Abstract}

This study describes the clinical characteristics and microscopic findings of nails from 25 patients with palmoplantar pustulosis. Methods: This is a cross-sectional study of adult patients with clear-cut palmoplantar pustulosis. Onychodystrophy severity was evaluated in fingernails using the nail psoriasis severity index (NAPSI). A fragment of the most dystrophic fingernail was collected from each patient and submitted to routine histotechnical processing. The following microscopic parameters were evaluated: nail plate and subungual region thickness, presence or absence of parakeratosis, number of layers of parakeratosis, and presence of neutrophils, serous lakes, bacteria, blood, and fungi. Results: Twenty-one patients (84\%) presented onychodystrophy with a mean NAPSI score of 12.67 . The most common nail change was pitting (76.19\% of patients). On average, nail plate thickness and subungual region thickness measured 0.42 and $0.14 \mathrm{~mm}$, respectively. Neutrophils and fungi were not observed, but serous lakes were found in $4.7 \%$, bacteria in $28.57 \%$, blood in $4.76 \%$, and parakeratosis in $19.05 \%$ of the patients. Conclusions: although palmoplantar pustulosis is a disease with great amounts of neutrophils in the epidermis, those cells were not found in the nail clippings studied herein. Furthermore, when clinical aspects and microscopic findings of palmoplantar pustulosis are compared to those of similar studies in psoriasis vulgaris, they show different characteristics. 
Tanaka et al.: Microscopic Examination of Nails in Palmoplantar Pustulosis

\section{Introduction}

Palmoplantar pustulosis represents a localized form of psoriasis with an estimated prevalence of $0.01-0.05 \%$ [1-5]. The involvement of nails is frequent in patients with psoriasis and is found in approximately $56 \%$ of cases in psoriasis vulgar [6], the most common cutaneous manifestation, whereas in palmoplantar pustulosis it occurs in $30-76 \%$ of patients [7]. The main goal of the present study is to describe the microscopic findings and clinical characteristics of nails from patients with palmoplantar pustulosis. To the best of our knowledge, this is the first detailed study describing nail changes associated with this specific form of psoriasis in the literature.

\section{Methods}

This is a cross-sectional study of patients diagnosed with palmoplantar pustulosis [3] and followed up in a dermatology outpatient hospital in Brazil (Hospital Universitário Evangélico de Curitiba, Paraná).

Patients were selected between August 2016 and August 2017 (consecutive cases) and data such as age, sex, duration of disease, and presence or absence of arthritis were collected. Onychodystrophy severity was evaluated in fingernails using the nail psoriasis severity index (NAPSI) [8].

A fragment of the most dystrophic fingernail was collected from each patient. When nails were clinically normal, nail fragments were systematically collected from the second finger of the nondominant hand.

Nail clipping was performed by cutting the distal portion of the free edge of the nail plate, with a minimum size of $5 \mathrm{~mm}$ in length and $2 \mathrm{~mm}$ in width $[9,10]$. The nail samples were technically processed for microscopic observation as previously described [11]. The following microscopic parameters were evaluated: nail plate and subungual region thickness (measured in millimeters using an appropriate ruler), presence or absence of parakeratosis (corneocyte nuclei at the subungual region), number of layers of parakeratosis, and presence of neutrophils, serous lakes, bacteria, blood, and fungi. Microscopic examination was performed blindly.

Categorical variables, with nominal or ordinal measurement scales, were analyzed using

the $\chi^{2}$ test, or Fisher's exact test when the $\chi^{2}$ test could not be applied. Quantitative variables were analyzed using the Mann-Whitney test. When significant differences were observed, supplementary comparisons were performed using the least significant difference test. All tests were performed at $p \leq 0.05$.

\section{Results}

Twenty-five patients with palmoplantar pustulosis were included. Twenty-two were women and 3 were men, with ages varying between 18 and 74 years ( $46.24 \pm 13.68$ years). The duration of the disease ranged from 6 months to 19 years ( $6.6 \pm 7.73$ years). Arthritis was recorded in $16 \%$ of the patients.

Twenty-one patients (84\%) presented onychodystrophy with NAPSI scores varying from 5 to $23(12.67 \pm 5.16)$. The most common nail changes were pitting $(76.19 \%)$, leukonychia (38.1\%), onycholysis (33.33\%), crumbling and splinter hemorrhages (23.81\%), Beau's lines (14.29\%), oil drop discoloration, and red spots in the lunula $(9.52 \%)$.

The microscopic thickness of the nail plate ranged from 0.2 to $0.8 \mathrm{~mm}(0.42 \pm 0.17 \mathrm{~mm})$, and that of the subungual region from 0 to $0.6 \mathrm{~mm}(0.14 \pm 0.16 \mathrm{~mm})$. 
Fig. 1. Dystrophic nail from a patient with palmoplantar psoriasis showing a thick subungual region with blood. HE. Original magnification, $\times 20$.

Fig. 2. Dystrophic nail from a patient with palmoplantar psoriasis depicting prominent arching of the nail transition zone. HE. Original magnification, $\times 10$.
Tanaka et al.: Microscopic Examination of Nails in Palmoplantar Pustulosis
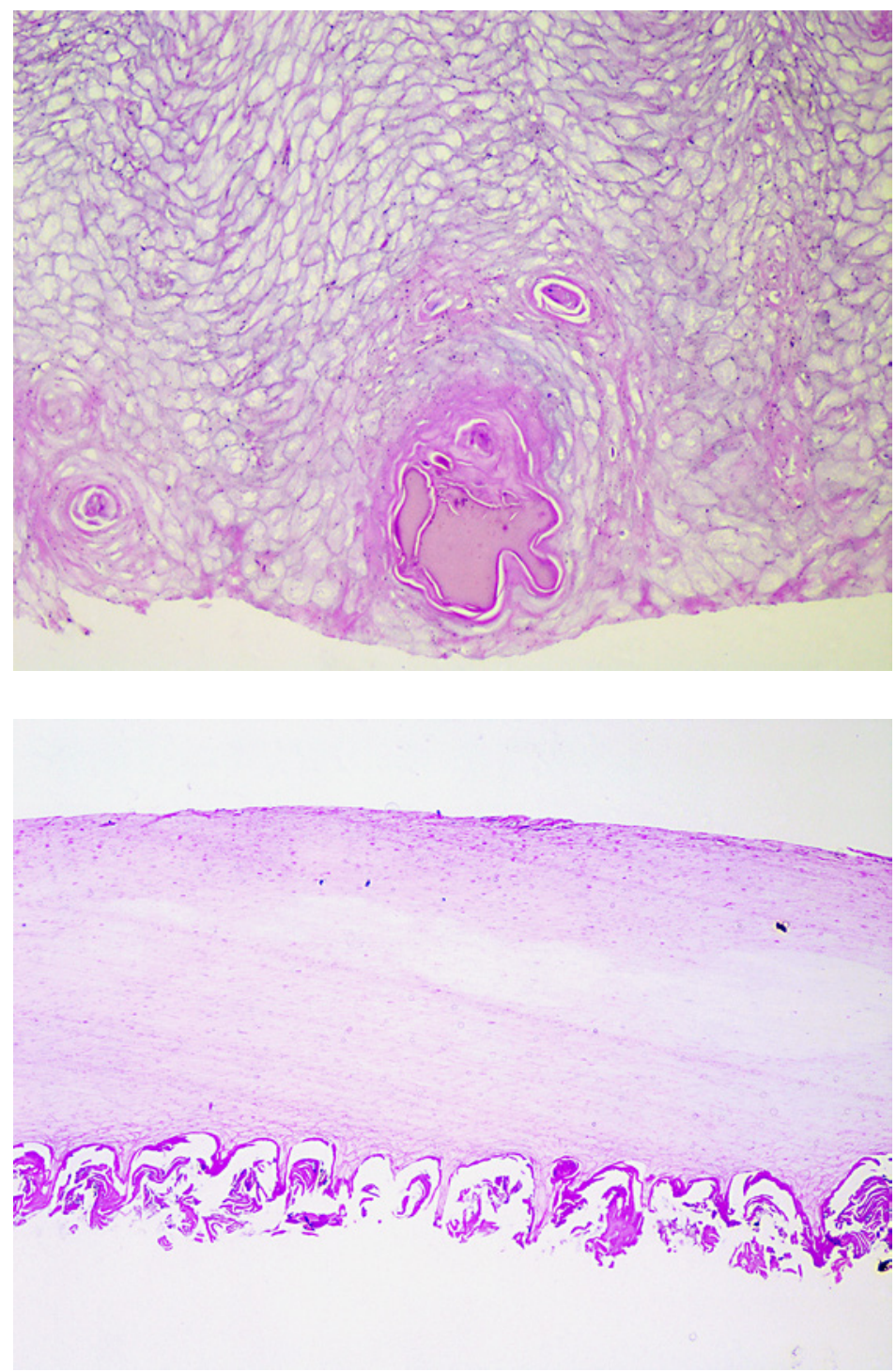

Neutrophils and fungi were not observed, but serous lakes were found in $4.7 \%$, bacteria in $28.57 \%$, blood in $4.76 \%$, and parakeratosis in $19.05 \%$ of the patients (number of layers varying from 3 to 6 , mean: 4.25). Prominent arching of the nail transition zone was observed in $9.52 \%$ of the patients with onychodystrophy. Some microscopic findings can be seen in Figures 1 and 2 .

\section{Discussion}

Palmoplantar pustulosis shares many features with psoriasis vulgaris, and about one third of patients with palmoplantar pustulosis present typical psoriasis lesions elsewhere in the body (skin, nail, or joint changes). However, on a genetic level, one of the major allelic determinants of psoriasis susceptibility - the psoriasis susceptibility locus (PSORS) 1 , which carries HLA-Cw*0602 - has not been found to be involved in the development of palmoplantar pustulosis [2-5]. Moreover, patients with palmoplantar pustulosis do not respond as 
Tanaka et al.: Microscopic Examination of Nails in Palmoplantar Pustulosis

Table 1. Comparison of microscopic nail clipping findings in patients with psoriasis vulgaris and onychodystrophy and patients with palmoplantar pustulosis and onychodystrophy

\begin{tabular}{lll}
\hline & $\begin{array}{l}\text { Psoriasis } \\
\text { vulgaris } \\
(n=50)\end{array}$ & $\begin{array}{l}\text { Palmoplantar } \\
\text { pustulosis } \\
(n=21)\end{array}$ \\
\hline Nail plate thickness, mm & $0.44 \pm 0.14$ & $0.42 \pm 0.17$ \\
Subungual thickness, mm & $0.19 \pm 0.15$ & $0.14 \pm 0.16$ \\
Layers of corneocytes, $n$ & $6.9 \pm 8.12$ & $4.25 \pm 1.26$ \\
Neutrophils & 12 & 0 \\
Serous lakes & 46 & $5^{\mathrm{a}}$ \\
Blood & 12 & $5^{\mathrm{a}}$ \\
Bacteria & 74 & $29^{\mathrm{a}}$ \\
\hline
\end{tabular}

Data are presented as mean \pm SD or percentage, as appropriate. a Percentages were rounded.

well to the therapies usually employed in psoriasis vulgaris, and differ by having a female predominance and a stronger association with smoking.

In the population analyzed in this study, we found a much higher incidence of the disease in women (88\%), with an average age of 46 years, when compared to reports from the literature $[12,13]$. On the other hand, the average duration of disease and arthritis rates are in agreement with previous reports $[14,15]$.

Nail changes were observed in $84 \%$ of our patients, which is a higher percentage than the $30 \%$ found in other studies for palmoplantar pustulosis $[7,16]$. The reason for this elevated rate in the onychodystrophy index could not be determined. Some possible reasons are (a) the small number of studies that have examined patients with palmoplantar pustulosis, preventing the establishment of reliable statistics; (b) the focus of the study on nail changes in this particular population; and (c) since this is the first study to analyze palmoplantar pustulosis patients in Brazil, the results could indicate a characteristic genetic profile more prone to onychodystrophy in Southern Brazil.

Most patients with onychodystrophy due to palmoplantar pustulosis from previous studies presented alterations due to nail matrix involvement. Burden and Kemmett [16] observed onycholysis and pitting in almost $40 \%$ of patients with that disease, and another study [7] found that $42.9 \%$ of patients presented pitting and $50 \%$ presented onycholysis. We observed similar results, finding pitting and onycholysis in 76 and $33 \%$ of our patients, respectively.

The average NAPSI for patients with pustulosis palmoplantar is not mentioned in the literature, but in this research we found an average of 12.67. Published data of NAPSI values for psoriasis vulgaris are variable according to the study, with scores ranging from 26.6 to 30.6 $[17,18]$. A comparison of these values between the two forms of psoriasis should be conducted very cautiously, though, because the methods chosen for evaluation vary among studies.

Some studies claim that severity in nail involvement is a predictor of psoriatic arthritis prevalence [19], although common nail and joint autoantigens were never identified [20, 21]. Coincidently or not, we found a low prevalence of arthritis among our patients (16\%) and a low NAPSI index (12.67 on average). Other authors [13] report a prevalence of 13-64\% of arthritis in pustulosis palmoplantar, and some studies have demonstrated a greater nail involvement (high NAPSI score) in patients with psoriatic arthritis [19].

Few studies have reported microscopic observations of nail changes in nail inflammatory diseases [22-26]. Specific studies that have examined psoriasis are even rarer. Machler et al. [22] were the first to describe nail microscopic findings for psoriasis, reporting the presence of parakeratosis and neutrophils without other microscopic details. Werner et al. [23] 
described detailed nail microscopic findings of dystrophic nails from patients with psoriasis. A comparison between the microscopic changes observed in patients with psoriasis vulgaris by Werner et al. [23] and in patients with palmoplantar pustulosis from the present study is presented in Table 1. In general, it appears that nails in palmoplantar pustulosis are microscopically less altered than those in psoriasis vulgaris. This could be an explanation for the low NAPSI score found in this study.

Neutrophils are important cells in the physiopathology of palmoplantar pustulosis. The characteristic pustules of the disease consist of large intraepidermal collections of neutrophils. T-cell infiltrates in the dermis and epidermis play another important role, secreting several cytokines (IFN- $\gamma$, IL-6, IL-17, and TNF- $\alpha$ ) that act as inflammation drivers in palmoplantar pustulosis [27]. Interestingly, whereas neutrophils were observed in nails of $12 \%$ of the patients with psoriasis vulgaris [23], they were never observed in nails from patients with palmoplantar pustulosis. This is likely a paradox, since palmoplantar pustulosis is the putative form of psoriasis presenting more neutrophils, and characteristically involves fingers and toes, close to the nail apparatus [22].

In conclusion, to the best of our knowledge, palmoplantar pustulosis presents less severe onychodystrophy and different microscopic characteristics when compared to psoriasis vulgaris. NAPSI seems to be lower in palmoplantar pustulosis and there is higher incidence of neutrophils, bacteria, and serous lakes, and more prominent parakeratosis in nails from patients with psoriasis vulgaris. Maybe our results add up to the differences between palmoplantar pustulosis and psoriasis vulgaris, as indicated by the already described distinct genotypic and phenotypic findings, and the low response to therapies regularly used in the treatment of the latter.

\section{Acknowledgments}

The authors thank Andre Antunes, histotechnician, for being deeply committed to his profession. They are also grateful to Dr. Lincoln Fabricio, Professor of Dermatology from Hospital Evangélico de Curitiba, Faculdade Evangélica do Paraná, for technical and academic support in performing this research, and the Brazilian Society of Dermatology for encouraging research.

\section{Statement of Ethics}

Subjects gave their written informed consent. The study was approved by the local Research Ethics Committee (Registration No. 1.601.733).

\section{Disclosure Statement}

The authors have no conflicts of interest to declare.

\section{Funding Sources}

This study was sponsored by the Support Fund for Dermatology (Funaderm), Brazilian Society of Dermatology. The research fund follows the rule search of the Brazilian federal government. 


\section{Author Contributions}

Anber A. Tanaka and Betina Werner: substantial contributions to the conception and design of the work; the acquisition, analysis, and interpretation of data; and drafting and revising the work. Cassio Tornesy and Cassia Farris: substantial contributions to the acquisition, analysis, and interpretation of data, and drafting and revising the work.

All authors agreed to be accountable for all aspects of the work and approved the final version.

\section{References}

1 Mrowietz U, van de Kerkhof PC. Management of palmoplantar pustulosis: do we need to change? Br J Dermatol. 2011 May; 164(5):942-6.

2 Sugiura K. The genetic background of generalized pustular psoriasis: IL36RN mutations and CARD14 gain-offunction variants. J Dermatol Sci. 2014 Jun;74(3):187-92.

3 Navarini AA, Burden AD, Capon F, Mrowietz U, Puig L, Köks S, et al.; ERASPEN Network. European consensus statement on phenotypes of pustular psoriasis. J Eur Acad Dermatol Venereol. 2017 Nov;31(11):1792-9.

4 Farley E, Masrour S, McKey J, Menter A. Palmoplantar psoriasis: a phenotypical and clinical review with introduction of a new quality-of-life assessment tool. J Am Acad Dermatol. 2009 Jun;60(6):1024-31.

5 Adișen E, Tekin 0, Gülekon A, Gürer MA. A retrospective analysis of treatment responses of palmoplantar psoriasis in 114 patients. J Eur Acad Dermatol Venereol. 2009 Jul;23(7):814-9.

6 Uber M, Carvalho VO, Abagge KT, Robl Imoto R, Werner B. Clinical features and nail clippings in 52 children with psoriasis. Pediatr Dermatol. 2018 Mar;35(2):202-7.

7 Hiraiwa T, Yamamoto T. Nail involvement associated with palmoplantar pustulosis. Int J Dermatol. 2017 Feb; 56(2):e28-9.

8 Rich P, Scher RK. Nail Psoriasis Severity Index: a useful tool for evaluation of nail psoriasis. J Am Acad Dermatol. 2003 Aug;49(2):206-12.

9 Fillus Neto J, Tchornobay AM. How the nail clipping helps the dermatologist [Como o clipping pode auxiliar o dermatologista]. An Bras Dermatol. 2009;84(2):173-6. English, Portuguese.

10 Stephen S, Tosti A, Rubin AI. Diagnostic applications of nail clippings. Dermatol Clin. 2015 Apr;33(2):289-301.

11 Werner B, Antunes A. Microscopic examination of normal nail clippings. Dermatol Pract Concept. 2013 Jul; 3(3):9-14.

12 Olazagasti JM, Ma JE, Wetter DA. Clinical Features, Etiologic Factors, Associated Disorders, and Treatment of Palmoplantar Pustulosis: The Mayo Clinic Experience, 1996-2013. Mayo Clin Proc. 2017 Sep;92(9):1351-8.

13 Brunasso AM, Puntoni M, Aberer W, Delfino C, Fancelli L, Massone C. Clinical and epidemiological comparison of patients affected by palmoplantar plaque psoriasis and palmoplantar pustulosis: a case series study. Br J Dermatol. 2013 Jun;168(6):1243-51.

14 Michaëlsson G, Kristjánsson G, Pihl Lundin I, Hagforsen E. Palmoplantar pustulosis and gluten sensitivity: a study of serum antibodies against gliadin and tissue transglutaminase, the duodenal mucosa and effects of gluten-free diet. Br J Dermatol. 2007 Apr;156(4):659-66.

15 Richer V, Roubille C, Fleming P, Starnino T, McCourt C, McFarlane A, et al. Psoriasis and Smoking: A Systematic Literature Review and Meta-Analysis with Qualitative Analysis of Effect of Smoking on Psoriasis Severity. J Cutan Med Surg. 2016 May;20(3):221-7.

16 Burden AD, Kemmett D. The spectrum of nail involvement in palmoplantar pustulosis. Br J Dermatol. 1996 Jun;134(6):1079-82.

17 Brazzelli V, Carugno A, Alborghetti A, Grasso V, Cananzi R, Fornara L, et al. Prevalence, severity and clinical features of psoriasis in fingernails and toenails in adult patients: italian experience. J Eur Acad Dermatol Venereol. 2012 Nov;26(11):1354-9.

18 van der Velden HM, Klaassen KM, van de Kerkhof PC, Pasch MC. Fingernail psoriasis reconsidered: a casecontrol study. J Am Acad Dermatol. 2013 Aug;69(2):245-52.

19 Maejima H, Taniguchi T, Watarai A, Katsuoka K. Evaluation of nail disease in psoriatic arthritis by using a modified nail psoriasis severity score index. Int J Dermatol. 2010 Aug;49(8):901-6.

20 McGonagle D, Benjamin M, Tan AL. The pathogenesis of psoriatic arthritis and associated nail disease: not autoimmune after all? Curr Opin Rheumatol. 2009 Jul;21(4):340-7.

21 McGonagle D, Palmou Fontana N, Tan AL, Benjamin M. Nailing down the genetic and immunological basis for psoriatic disease. Dermatology. 2010;221 Suppl 1:15-22.

22 Machler BC, Kirsner RS, Elgart GW. Routine histologic examination for the diagnosis of onychomycosis: an evaluation of sensitivity and specificity. Cutis. 1998 Apr;61(4):217-9.

23 Werner B, Fonseca GP, Seidel G. Microscopic nail clipping findings in patients with psoriasis. Am J Dermatopathol. 2015 Jun;37(6):429-39. 
24 Laporte M, André J, Stouffs-Vanhoof F, Achten G. Nail changes in alopecia areata: light and electron microscopy. Arch Dermatol Res. 1988;280 Suppl:S85-9.

25 Miteva M, de Farias DC, Zaiac M, Romanelli P, Tosti A. Nail clipping diagnosis of onychomatricoma. Arch Dermatol. 2011 Sep;147(9):1117-8.

26 Lin AM, Rubin CJ, Khandpur R, Wang JY, Riblett M, Yalavarthi S, et al. Mast cells and neutrophils release IL-17 through extracellular trap formation in psoriasis. J Immunol. 2011 Jul;187(1):490-500.

27 Murakami M, Hagforsen E, Morhenn V, Ishida-Yamamoto A, Iizuka H. Patients with palmoplantar pustulosis have increased IL-17 and IL-22 levels both in the lesion and serum. Exp Dermatol. 2011 Oct;20(10):845-7. 